\title{
Rendimentos do processamento e composição química de filés de surubim cultivado em tanques-rede
}

\section{Denilson Burkert ${ }^{1}$, Dalcio Ricardo de Andrade ${ }^{2}$, Rodolfo Nardez Sirol ${ }^{3}$, Ana Lúcia Salaro4, José Eduardo de Aracena Rasguido5, Célia Raquel Quirino6}

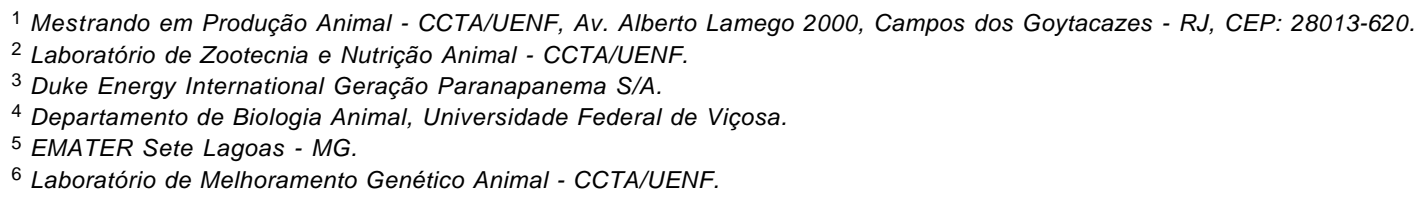

RESUMO - Neste trabalho foi avaliado o efeito da utilização de três rações comerciais indicadas para alimentação de peixes carnívoros sobre os rendimentos do processamento e a composição de filés de surubim (Pseudoplatystoma sp) cultivados em tanques-rede. Os surubins foram cultivados em tanques-rede durante um ano, período em que foram alimentados com três rações contendo 43,5; 42,6 e 42,1\% de proteína bruta; 6,3; 8,7 e 4,5\% de extrato etéreo e 5.078; 4.931 e 4.994 kcal de energia bruta, respectivamente, em um delineamento inteiramente casualizado, com três tratamentos e três repetições. Em cada tanque, foram selecionados cinco peixes com pesos entre 1.280 e $1.340 \mathrm{~g}$, que foram insensibilizados e sacrificados para determinação dos rendimentos de carcaça com e sem pele, cabeça, filé total, lateral e abdominal, fígado, pele e esqueleto. Amostras de filés laterais e abdominais foram tomadas para análises bromatológicas. Foram avaliados 22 fêmeas e 23 machos, no entanto, não foi observada diferença entre os sexos quanto aos principais rendimentos de processamento. Os rendimentos de filé abdominal e de resíduos com e sem pele diferiram entre as rações. A composição bromatológica dos filés (lateral e abdominal) não foi influenciada pelas rações e não diferiu entre os cortes. A utilização de rações comerciais no cultivo não acarretou mudanças na quantidade e na qualidade dos principais cortes do surubim.

Palavras-chave: processamento, Pseudoplatystoma, rendimento, surubim, tanque-rede

\section{Processing yield and chemical composition of fillets of surubim reared in net cages}

\begin{abstract}
The objective of this work was to evaluate the effect of three commercial feeds recommended for carnivorous fish on processing yield and fillet composition of surubim (Pseudoplatystoma $\mathrm{s} p$ ) raised in net cages. The surubim fishes were raised in net cages during one year, when were fed three diets with $43.5,42.6$, and $42.1 \%$ crude protein; $6.3,8.7$, and $4.5 \%$ ether extract and 5,078, 4,931, and 4,994 kcal of gross energy, respectively. Fishes were allotted to a completely randomized design, with three treatments and three replicates. Five surubim fishes weighing from 1280 to $1340 \mathrm{~g}$ were selected from each cage and unsensibilized and slaughtered for posterior determination of the processing yields of carcass with and without skin, head, total fillet, lateral and abdominal fillets, liver, skin and skeleton. Samples of lateral and abdominal fillets were colleted to determine their chemical analyses. No differences were observed between sexes for the principal processing yields, in a total of 22 females and 23 males. There was difference in the abdominal fillet and of the residues with and without skin among diets. There was difference in the abdominal fillet and of the residues with and without skin among diets. The use of different commercial diets during the raising period did not affect the amount and quality of principal edible cuts of surubim fish.
\end{abstract}

Key Words: cage, dressing out, Pseudoplatystoma, surubim, yield

\section{Introdução}

A busca por produtos de fácil preparo, higienicamente corretos e nutricionalmente adequados (Oetterer, 2002) tem sido crescente entre consumidores, o que tem contribuído para o desenvolvimento do consumo de pescado no Brasil e possibilitado o crescimento da piscicultura no País, uma atividade que tem se adequado às necessidades de mercado com alternativas para o processamento de peixes visando agregação de valor aos produtos comercializados. 
Segundo Lanari et al. (1999), futuramente a produção aqüícola será voltada principalmente aos produtos processados. Assim, o conhecimento do rendimento de carcaça e das proporções de filé e demais subprodutos de peixes permitirá que a indústria processadora faça exploração mais eficiente desses recursos.

O rendimento de partes comestíveis tem se tornado um dos critérios para a escolha dos peixes cultivados. São procuradas espécies com altos rendimentos da porção comestível. De acordo com Contreras-Guzmán (1994), o rendimento médio de carcaça de peixes comerciais de água doce e salgada é de $62,6 \%$, enquanto em algumas espécies de água doce a porção comestível pode representar até 75,3\% do peso corporal (Bressan, 1999).

Peixes do gênero Pseudoplatystoma, conhecidos como pintado, cachara ou simplesmente surubim, são apreciados pela ausência de espinhas em seus filés e pela carne considerada de excelente qualidade, com coloração clara e textura firme (Tavares, 1997). De acordo com Kubitza (1998), a expansão do consumo de surubins torna esta espécie de grande interesse comercial, o que contribui para o desenvolvimento de sua produção em cativeiro. Segundo Ribeiro $\&$ Miranda (1997), o rendimento médio de carcaça de surubins (P. coruscans) provenientes de pesca é de $71,33 \%$, o que caracteriza essa espécie como de grande potencial para a piscicultura brasileira. As características de rendimento de carcaça e de filé têm contribuído para o cultivo de surubins em diversos sistemas de produção aquícola, inclusive em tanques-rede.

Independentemente da espécie e da forma de cultivo, o principal interesse do aqüicultor ainda está relacionado ao peso do peixe a ser entregue à indústria e à quantidade de carne que será disponibilizada ao final do processamento.

As características de composição química da carne de peixes ainda não são de grande interesse, no entanto, segundo Santos et al. (2001), a obtenção desses dados é importante nos processos de conservação e elaboração do produto.

A composição química da carne de um peixe depende de fatores bióticos e abióticos relacionados à espécie e ao cultivo, que influenciam as características físicas e organolépticas e o tempo de prateleira do peixe e de seus derivados.

Entre esses fatores, a ração é muito importante, pois, quando formulada adequadamente, permite maior eficiência no uso de seus nutrientes tornando a composição química do corpo e da carne de peixes mais apropriada para conservação e para o consumo humano.

Este trabalho foi realizado visando à avaliação dos efeitos do uso de três rações comerciais sobre os rendimentos e a composição dos filés de surubins (Pseudoplatystomasp) cultivados em tanques-rede.

\section{Material e Métodos}

Um cultivo experimental do surubim (Pseudoplatystoma sp) em tanques-rede foi realizado durante um ano. Durante este cultivo, os peixes foram alimentados com três rações comerciais recomendadas para peixes carnívoros (Tabela 1 ). Foram utilizados nove tanques-rede, cada um com dimensões de $3 \times 3 \times 1,5 \mathrm{~m}$ (largura, comprimento e altura), totalizando um volume de $13,5 \mathrm{~m}^{3}$ e volume útil de $10,8 \mathrm{~m}^{3}$.

Em cada um dos tanques, foram introduzidos inicialmente 231 peixes com peso médio inicial de $175 \mathrm{~g}$. Cada uma das rações foi fornecida aos peixes mantidos em três tanques-redes, que corresponderam a três tratamentos (rações), cada um com três repetições (tanques-rede).

Ao final do cultivo, todos os peixes foram submetidos a jejum de 48 horas para esvaziamento do sistema gastrointestinal. Posteriormente, todos os peixes contidos nos tanques foram submetidos à biometria, efetuando-se as medidas de peso e comprimento. Em cada tanque, foram coletados cinco peixes com pesos entre 1.280 e $1.340 \mathrm{~g}$, totalizando 45 surubins (Pseudoplatystoma sp), portanto, 15 peixes de cada tratamento.

Após a separação, os peixes foram sacrificados pelo corte da medula espinhal e, em seguida, lavados. Então, iniciou-se a evisceração usando-se faca, tesoura e torquês, sempre por uma única pessoa, com a finalidade de se evitarem diferenças individuais nos rendimentos de cortes. Os rendimentos avaliados foram: rendimento de cabeça $(\mathrm{RC})=($ peso da cabeça $/$ peso total do peixe $) \times 100$; rendimento de carcaça $($ RCA1) $=($ peso de todo o corpo sem vísceras e nadadeiras / peso total do peixe $) \times 100$; rendimento de carcaça sem pele RCA2 - (rendimento de carcaça (RCA1) com exclusão da pele / peso total do peixe $) \times 100$; rendimento do filé lateral RFL - (rendimento dos dois filés localizados na região lateral do corpo do peixe, livre de couro/peso total do peixe) $\times 100$; rendimento do filé abdominal RFA - (rendimento dos dois filés localizados na região abdominal junto

Tabela 1 - Composição das rações comerciais utilizadas no experimento

\begin{tabular}{lccc}
\hline Item & \multicolumn{3}{c}{ Ração } \\
\cline { 2 - 4 } & 1 & 2 & 3 \\
\hline Proteína bruta (\%) & 43,5 & 42,6 & 42,1 \\
Extrato etéreo (\%) & 6,3 & 8,7 & 4,5 \\
Cinzas (\%) & 8,2 & 9,6 & 11,7 \\
Energia bruta (kcal) & $5.079,7$ & $4.930,6$ & $4.994,3$ \\
\hline
\end{tabular}

(C) 2008 Sociedade Brasileira de Zootecnia 
à base da nadadeira peitoral / peso total do peixe) $\times 100$; rendimento do filé total RFT - a soma dos rendimentos de filé lateral RFL e filé abdominal RFA; rendimento de fígado $\mathrm{RF}-$ (peso do fígado / peso total do peixe) $\times 100$; rendimento de resíduo RES1 - (peso de todo material excluído durante o processamento, entre ele, vísceras, nadadeiras, pele, sangue e água / peso total do peixe $\times 100$; rendimento de resíduo sem pele RES2 - (rendimento de resíduo 1 (RES1) com exclusão da pele/ peso total do peixe $) \times 100$; rendimento de pele RP - (peso da pele/ peso total do peixe $) \times 100$; rendimento de esqueleto RESQ - (peso do esqueleto / peso total do peixe) $\times 100$.

Foram extraídas apenas as extremidades das nadadeiras para permitir o melhor aproveitamento da parte posterior ao pedúnculo caudal, assim como sugerido por Ribeiro \& Miranda (1997). Para obtenção dos filés laterais, retirou-se a pele dos peixes e efetuou-se um corte do músculo dorsolateral no sentido longitudinal, ao longo de toda a coluna vertebral da porção cranial até o final do pedúnculo caudal, realizado do sentido do dorso em direção ao ventre do animal. Os filés abdominais foram seccionados da região junto à base das nadadeiras peitorais em direção à base das costelas.

Para as análises laboratoriais de composição química, foram coletados três filés laterais e três abdominais de peixes pertencentes a cada repetição. Cada conjunto de filés laterais e abdominais foi acondicionado em sacos plásticos separados e submetido a um processo de conge lamento rápido e permaneceram dessa forma até o momento das análises. Para as análises laboratoriais, realizou-se um processo de descongelamento lento dos conjuntos e, posteriormente, efetuaram-se cortes transversais visando à formação de amostras de peso comum, as quais foram processadas em liqüidificador. Depois desse procedimento, todas as amostras foram pesadas e submetidas a um processo de pré-desengorduramento em éter de petróleo, no qual toda a gordura retirada foi posteriormente somada aos valores obtidos ao final da extração do extrato etéreo. Em seguida, o material foi seco em estufa a $80^{\circ} \mathrm{C}$ por 24 horas para determinação dos teores de matéria seca, proteína bruta (método Kjeldahl com o fator de conversão de nitrogênio para proteína de 6,25), extrato etéreo (método Soxhlet) e cinzas (em mufla a $120^{\circ} \mathrm{C}$ ) de acordo com Silva (1990).

Verificou-se a consistência dos dados e realizou-se a análise preliminar dos efeitos do fator tratamento sobre as características consideradas no estudo. Os rendimentos do processamento foram verificados de acordo com o modelo inteiramente casualizado com três tratamentos (rações) e três repetições (tanques).Foram obtidas também as corre- lações simples com nível de significância de 5\% entre as características de rendimento do processamento estudadas, juntamente com o comprimento e o peso total. A composição dos filés dos peixes foi avaliada segundo o esquema fatorial $3 \times 2$, com três tratamentos (rações), em função dos dois cortes (lateral e abdominal), utilizando-se análise de variância seguida da aplicação de teste de Tukey $(\mathrm{P}<0,05)$ entre os tratamentos e interação, quando necessário.

\section{Resultados e Discussão}

A determinação dos rendimentos de filé lateral e filé abdominal, carcaça sem pele, fígado, esqueleto e pele do surubim Pseudoplatystoma sp. foi proposta visando à possível identificação de diferenças, tanto na composição química quanto na distribuição dos cortes realizados. Essas diferenças podem em algum momento contribuir para a agregação de valor ao surubim, além de servirem como possíveis parâmetros da eficiência da produção e do processamento desses peixes.

Os dados obtidos foram provenientes de 22 fêmeas e 23 machos de surubim. Os peixes amostrados neste experimento tinham peso médio de $1.367 \pm 59,74 \mathrm{~g}$ e apresentavam gônadas em estádio de desenvolvimento ainda inicial, as quais corresponderam a $0,53 \pm 0,32 \%$ do peso dos peixes. Os índices gonadassomáticos, tanto de machos como de fêmeas, não diferiram estatisticamente entre os tratamentos utilizados.

Apenas os rendimentos de cabeça (RC) e de fígado (RF) foram estatisticamente diferentes entre os sexos. As fêmeas apresentaram maior rendimento de cabeça, enquanto os machos apresentaram maior rendimento de fígado (Tabela 2). Esses dados comprovam que os principais rendimentos de processamento de surubins nesta fase de crescimento apresentam valores semelhantes em ambos os sexos, diferentemente do que ocorre com as traíras, Hoplias malabaricus (Santos et al., 2000), nas quais o rendimento de filé é maior nos machos.

Os valores médios dos rendimentos de cabeça (RC) e de filé total (RFT) obtidos neste trabalho foram 17,07 e 47,79\%, respectivamente, similares aos obtidos por Ribeiro \& Miranda (1997). A modificação sugerida por estes autores, ou seja, a retirada apenas das extremidades da nadadeira caudal mantendo a maior porção do pedúnculo caudal, possibilitou o aumento dos valores de RCA1, os quais atingiram 73,31\% e acarretaram a diminuição dos valores de RES1, chegando a 18,31\%, o que evidencia que a estratégia proposta é vantajosa, pois garante maior ganho de peso para a carcaça e a redução da produção de resíduos. 
Com a retirada da pele, o rendimento médio de carcaça foi de $66,98 \%$. Esses valores estão de acordo com os descritos por Bressan (1999) como rendimentos da porção comestível de algumas espécies de água doce e são superiores aos obtidos por Carneiro et al. (2004) no processamento do jundiá, Rhamdia quelen, de $60,31 \%$ de rendimento médio da carcaça eviscerada e sem cabeça.

A carcaça sem pele pode contribuir para o estabelecimento de um parâmetro para avaliação da qualidade do processamento de surubim, uma vez que é o primeiro corte concluído desde o início dos procedimentos de evisceração do surubim e, conseqüentemente, possui menor custo de elaboração.

Outra iniciativa tomada neste estudo foi a divisão do filé limpo total em filés lateral e abdominal, de forma semelhante à usada por Caraciolo et al. (2000), que propuseram a separação dos filés do tambaqui Colossoma macropomum em dorso-lateral e abdominal. em dorsolateral e abdominal. Esta prática foi realizada por esses autores com o objetivo de produzir cortes com caracterís ticas diferenciadas e, com isto, aumentar o valor de mercado, o que pode tornar a produção do tambaqui mais atraente.

Os filés do surubim corresponderam, em média, a $47,79 \%$ do peso dos peixes; $35,57 \%$ do peso foi representado pelos filés laterais e 12,22\% pelos filés abdominais. Entre os rendimentos de filé estudados, foram encontradas diferenças significativas relacionadas às rações utilizadas somente nos filés abdominais, uma vez que os peixes alimentados com as rações 1 e 3 apresentaram maior produção. Por outro lado, entre os peixes alimentados com as rações 1 e 2 foram encontrados maiores rendimentos de resíduo, o que provavelmente foi resultado da maior produção de filés abdominais.
Apesar das diferenças nos rendimentos obtidos com as três rações utilizadas, a ocorrência de variações nas composições desses alimentos durante o experimento não permite a identificação exata dos fatores que afetaram decisivamente esses rendimentos.

Os resíduos com pele (RES1) correspondem a 24,64\% do peso total dos peixes amostrados e a pele corresponde a 6,33\% do peso. Os valores da participação da pele no peso total dos surubins estão de acordo com o citado por Souza (2002) para a maior parte dos peixes. Segundo ContrerasGuzmán (1994), a pele participa em média com 7,5\% do peso dos peixes brasileiros.

O esqueleto também tem relativa participação no rendimento dos resíduos destes peixes (em média 19,19\%) e corresponde à fração de maior dificuldade no aproveitamento, em virtude de sua dureza (Ogawa \& Maia, 1999), e pode ser aproveitado na forma de farinha ou de fertilizantes.

A produção de matéria comestível representada pelo percentual de filé limpo total nos surubins foi superior à encontrada no jundiá estudado por Carneiro et al. (2003), que obtiveram o valor médio de $34,75 \%$ de filé (lateral) e de até $11,22 \%$ de filé abdominal, totalizando $45,97 \%$ do peso dos peixes. $\mathrm{O}$ valor médio de filé total obtido neste experimento foi de 47,79 $\pm 2,33 \%$, superior ao descrito por Argue et al. (2003), que avaliaram os rendimentos do processamento de diversos cruzamentos entre Ictalurus punctatus e Ictalurus furcatus e destas espécies com seus híbridos. Esses resultados comprovam que o rendimento do surubim é superior ao de espécies filogeneticamente próximas e exploradas na aqüicultura.

Os rendimentos de filé obtidos neste experimento foram inferiores ao encontrados por Ribeiro \& Miranda (1997), de $48,73 \%$. Os maiores valores obtidos por esses autores estão

Tabela 2 - Rendimentos do processamento de surubins alimentados com três rações comerciais

\begin{tabular}{|c|c|c|c|c|c|c|}
\hline \multirow{3}{*}{$\begin{array}{l}\text { Item } \\
\text { Característica }\end{array}$} & \multicolumn{5}{|c|}{ Efeito } & \multirow[b]{3}{*}{ Média geral } \\
\hline & \multicolumn{3}{|c|}{ Ração } & \multicolumn{2}{|c|}{ Sexo } & \\
\hline & 1 & 2 & 3 & Fêmea & Macho & \\
\hline Rendimento de carcaça 1 (RCA1) & $72,92 \pm 5,91 \mathrm{a}$ & $72,19 \pm 4,16 a$ & $74,82 \pm 2,32 \mathrm{a}$ & $73,89 \pm 2,84 \mathrm{a}$ & $72,71 \pm 5,65 a$ & $73,31 \pm 4,43$ \\
\hline Rendimento de carcaça 2 (RCA2) & $66,88 \pm 3,00 \mathrm{a}$ & $66,02 \pm 3,66 a$ & $68,04 \pm 1,75 \mathrm{a}$ & $66,57 \pm 2,85 a$ & $67,41 \pm 3,08 \mathrm{a}$ & $66,98 \pm 2,96$ \\
\hline Rendimento de cabeça (RC) & $17,34 \pm 1,15 \mathrm{a}$ & $16,72 \pm 1,12 \mathrm{a}$ & $17,17 \pm 0,95 \mathrm{a}$ & $17,60 \pm 1,03 \mathrm{a}$ & $16,52 \pm 0,86 b$ & $17,08 \pm 1,08$ \\
\hline Rendimento de filé abdominal (RFA) & $12,29 \pm 0,67 \mathrm{ab}$ & $11,86 \pm 0,69 b$ & $12,51 \pm 0,55 \mathrm{a}$ & $12,12 \pm 0,75 a$ & $12,33 \pm 0,61 \mathrm{a}$ & $12,22 \pm 0,68$ \\
\hline Rendimento de filé total (RFT) & $47,85 \pm 2,13 \mathrm{a}$ & $47,21 \pm 3,03 \mathrm{a}$ & $48,32 \pm 1,64 \mathrm{a}$ & $47,60 \pm 2,13 a$ & $48,00 \pm 2,56 a$ & $47,79 \pm 2,33$ \\
\hline Rendimento de fígado (RF) & $0,91 \pm 0,10 b$ & $1,24 \pm 0,30 \mathrm{a}$ & $1,10 \pm 0,17 \mathrm{a}$ & $1,01 \pm 0,20 \mathrm{~b}$ & $1,16 \pm 0,27 \mathrm{a}$ & $1,08 \pm 0,25$ \\
\hline Rendimento de resíduo 1 (RES1) & $24,99 \pm 4,14 \mathrm{ab}$ & $26,22 \pm 5,33 \mathrm{a}$ & $22,72 \pm 1,89 b$ & $24,44 \pm 3,97 a$ & $24,85 \pm 4,56 a$ & $24,64 \pm 5,49$ \\
\hline Rendimento de resíduo 2 (RES2) & $18,95 \pm 6,76 \mathrm{ab}$ & $20,05 \pm 5,75 a$ & $15,92 \pm 2,49 b$ & $17,12 \pm 4,13 \mathrm{a}$ & $19,55 \pm 6,49 a$ & $18,31 \pm 5,49$ \\
\hline Rendimento de pele (RP) & $8,43 \pm 3,24 \mathrm{a}$ & $6,16 \pm 3,37 b$ & $6,79 \pm 1,37 \mathrm{ab}$ & $7,32 \pm 1,86 a$ & $6,93 \pm 3,76 a$ & $7,13 \pm 2,92$ \\
\hline Rendimento de esqueleto (RESQ) & $19,03 \pm 1,60 a$ & $18,81 \pm 2,48 \mathrm{a}$ & $19,72 \pm 2,01 \mathrm{a}$ & $18,97 \pm 1,45 \mathrm{a}$ & $19,41 \pm 2,55 a$ & $19,19 \pm 2,05$ \\
\hline
\end{tabular}

Valores na linha seguidos de mesma letra não diferem $(P<0,05)$ significativamente pelo teste Tukey. 
relacionados, possivelmente, à maior deposição de gordura, ocorrida tanto na região celomática, evidenciada pelos maiores rendimentos de vísceras, quanto na musculatura, uma vez que os peixes apresentaram pesos superiores a $5 \mathrm{~kg}$, o que colaboraria para maior acúmulo de gordura. Além disso, os peixes avaliados por esses autores eram selvagens e, em virtude de uma alimentação desbalanceada, também poderiam apresentar maior deposição de gordura tanto na carcaça quanto nos filés.

Outra forma de agregação de valor aos surubins pode ser feita com o aproveitamento de seus fígados, uma vez que em animais com peso de $1.367 \mathrm{~g}$ esse órgão teria em torno de $14,77 \mathrm{~g}$. O aproveitamento pode ser interessante para o processamento porque, em razão de seu sabor característico, esse órgão é apreciado por uma parcela dos consumidores.

Foram observadas apenas quatro correlações consideradas de alta magnitude $(>0,70)$ e estatisticamente significativas entre os diversos rendimentos de processamento estudados (Figura 1a, b, c, d).

A correlação entre RCA1 e RES1 $(-0,88)$ foi negativa da mesma forma que RCA2 e o RES2 (-0,78), enquanto a correlação entre RFT e RCA2 $(0,72)$ e entre RFT e RFL $(0,95)$ foi positiva. Com base nesses resultados, pode-se observar tendência de que o aumento do rendimento de carcaça acarreta diminuição da quantidade de resíduos produzidos, principalmente o da pele. Além disso, o rendimento de carcaça sem pele é um bom parâmetro para determinação do rendimento de filé total e indiretamente para a produção de filé lateral.

Os rendimentos dos resíduos do processamento com e sem pele estiveram correlacionados significativamentecom a maioria das características estudadas, porém, em geral, essa correlação foi de baixa a média magnitude. Os valores de correlação corroboram, em parte, os obtidos por Ribeiro \& Miranda(1997), que observaram baixas e médias grandezas para a maior parte dos parâmetros estudados.

A análise bromatológica dos filés lateral e abdominal foi realizada com o intuito de avaliar possíveis diferenças em suas composições químicas, o que poderia determinar algum aspecto diferenciado de comercialização. No entanto, não houve diferença significativa na composição dos filés (Tabela 3).

De acordo com estes valores, pode se inferir que não há justificativa para a separação destes filés de acordo com sua composição. Entretanto, a ausência da musculatura marrom no filé abdominal permite a adoção de uma forma diferenciada de apresentação em relação ao seu sabor e a sua estética.

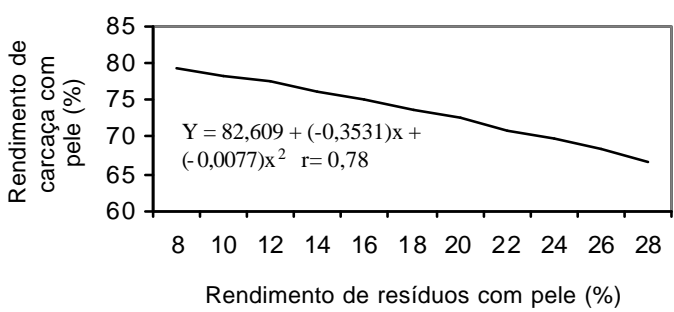

C

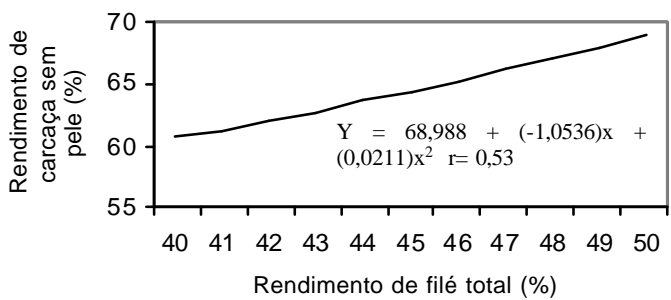

b

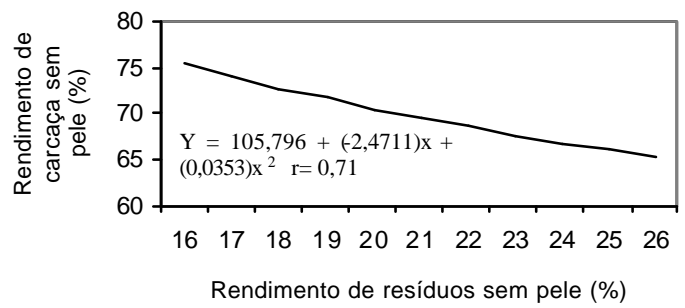

d

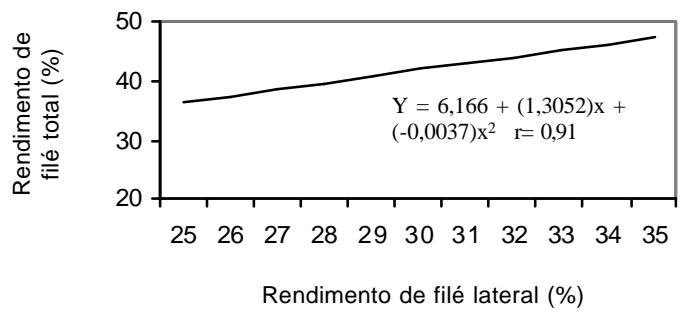

Figura 1 - Regressões quadráticas das correlações de alta magnitude observadas entre os diferentes rendimentos de processamento do surubim: a) rendimento de carcaça com pele $\times$ rendimento de resíduos com pele; b) rendimento de carcaça sem pele $\times$ rendimento de resíduos sem pele; c) rendimento de carcaça sem pele $\times$ rendimento de filé total; e d) rendimento de filé total $\times$ rendimento de filé lateral. 
Tabela 3 - Composição dos filés e cortes de surubins alimentados com três rações comerciais

\begin{tabular}{lcccc}
\hline Item & Umidade $(\%)$ & Proteína bruta $(\%)$ & Extrato etéreo $(\%)$ & Cinzas $(\%)$ \\
\hline File & & & & \\
Filé lateral & $64,83 \pm 2,35$ & $20,63 \pm 1,98$ & & $1,64 \pm 0,84$ \\
Filé abdominal & $63,43 \pm 1,75$ & $21,40 \pm 1,26$ & $1,29 \pm 0,48$ & $1,81 \pm 0,11$ \\
\hline Raçao & & & & $1,14 \pm 0,39$ \\
1 & $64,18 \pm 2,13$ & $20,09 \pm 0,68$ & $1,54 \pm 0,61$ & $1,54 \pm 0,43$ \\
2 & $62,85 \pm 2,18$ & $21,84 \pm 2,60$ & $1,80 \pm 0,89$ & $1,48 \pm 0,57$ \\
3 & $65,35 \pm 1,56$ & $21,11 \pm 0,55$ & $1,06 \pm 0,30$ & $1,40 \pm 0,39$ \\
\hline Valor médio geral & $64,13 \pm 2,13$ & $21,01 \pm 1,66$ & $1,47 \pm 0,69$ & $1,48 \pm 0,45$ \\
\hline
\end{tabular}

A interação cortes $\times$ tratamentos não foi significativa, assim como não houve diferença entre as composições dos filés entre as rações. A composição média dos filés do surubim cultivado em tanques-rede foi similar à de espécies do litoral brasileiro descritas por Contreras-Guzmán (1994) e também à da traíra Hoplias malabaricus (Santos et al., 2000) e do catfish Ictalurus punctatus (Ronbinson \& Li, 1997). Os valores de proteína foram superiores aos encontrados na carpa comum,Cyprinus carpio(Gerietal., 1995), o que torna o surubim um peixe de carne de melhor qualidade em comparação a espécies já cultivadas, ou seja, com maior quantidade de proteína por grama de peso, enquanto as concentrações de gordura e de minerais são similares as destas espécies.

\section{Conclusões}

O surubim Pseudoplatystoma sp., mesmo sob condições de cultivo intensivo, apresenta bons rendimentos de partes comestíveis com qualidade similar ou em algumas ocasiões superior à de espécies já exploradas na aqüicultura. As fêmeas do surubim apresentam maior rendimento de cabeça, enquanto os machos possuem maiores rendimentos de fígado quando alimentados com rações comerciais. As rações comerciais indicadas para alimentação de peixes carnívoros utilizadas neste experimento não promoveram alterações na composição química dos filés do surubim.

\section{Agradecimento}

À empresa Projeto Pacu Ltda., pela concessão dos peixes utilizados no experimento. À Querença Empresa Rural Agricultura e Pecuária Ltda., pela possibilidade da realização deste experimento. À Fundação de Amparo à Pesquisa do Estado do Rio de Janeiro - FAPERJ, pelo auxílio financeiro.

\section{Literatura Citada}

ARGUE, B.J.; LIU, Z.; DUNHAM, R.A. Dress-out and fillet yield of channel catfish, Ictalurus punctatus, blue catfish, Ictalurus furcatus, and their F e F and brackcross hybrids. Aquaculture, v.228, p.81-90, 2003.

BRESSAN, M.C. Tecnologia de pós-colheita em peixes. Curso de especialização Pós Graduação "Lato Sensu" Ensino à distância: Piscicultura: UFLA/FAEPE, 1999. 94p.

CARACIOLO, M.S.B.; KRUGER, S.R.; BRANCO, F.J.C.C. Avaliação do rendimento de carne do tambaqui (Colossoma macropomum). In: AQUICULTURABRASIL 2000; SIMPÓSIO BRASILEIRO DE AQUICULTURA, 11., 2000, Florianópolis. Anais... Florianópolis, 2000. (CD-ROM).

CARNEIRO, P.; MIKOS, J.D.; BENDHACK, F. Processamento - O jundiá como matéria-prima. Revista Panorama da Aqüicultura, v.13, n.78, p.17-21, 2003.

CARNEIRO, P.; MIKOS, J.D.; BENDHACK, F. et al. Processamento do jundiá Rhamdia quelen: rendimento de carcaça. Revista Acadêmica: Ciências Agrárias e Ambientais, v.2, n.3, p.1117, 2004.

CONTRERAS-GUZMÁN, E.S. Bioquímica de pescados e derivados Jaboticabal: Funep, 1994. 409p.

GERI, G.; POLI, B.M.; GUALTIERI, M. et al. Body traits and chemical composition as muscle in the common carp (Cyprinus carpio L.) as influenced by age and rearing environment. Aquaculture, v.129, p.329-333, 1995.

KUBITZA, F. Produção intensiva de surubins no Projeto Pacu Ltda. e Agropeixe Ltda. In: AQÜICULTURA BRASIL'98; CONGRESSO SUL-AMERICANO DE AQÜICULTURA, 1 ., 1998, Recife. Anais... Recife: 1998. p.447.

LANARI, D.; POLI, B.M.; BALLESTRAZI, R. et al. The effects of dietary fat and NFE levels on growing european sea bass (Dicentrarchus labrax L.). Growth rate, body and fillet composition, carcass traits and nutrient retention efficiency. Aquaculture, v.179, p.351-364, 1999.

OETTERER, M. Industrialização do pescado cultivado . Guaíba: Agropecuária, 2002. 200p

OGAWA, M.; MAIA, E.L. Manual de pesca. São Paulo: Livraria Varela, 1999. 430p.

RIBEIRO, L.P.; MIRANDA, M.O.T. Rendimentos de processamento do surubim Pseudoplatystoma coruscans. In: MIRANDA, M.O.T. (Ed.) Surubim. Belo Horizonte: Instituto Brasileiro do Meio Ambiente e dos Recursos Naturais, 1997. p.101-111.

ROBINSON, E.H.; LI, M.H. Low protein diets for channel catfish Ictalurus punctatus raised in earthen ponds at high density. Journal of World Aquaculture Society, v.28, n.3, p.224229, 1997. 
SANTOS, A.B.; MELO, J.F.B.; LOPES, P.R.S. et al. Composição química e rendimento do filé da traíra (Hoplias malabaricus). Revista da Faculdade de Zootecnia, Veterinária e Agronomia, v.7, n.1, p.33-39, 2001.

SILVA, D.J. Análise de alimentos (Métodos químicos e biológicos). Viçosa: Editora UFV, 1990. 165p.

SOUZA, M.L.R.; LIMA, S.; PINTO, A.A. et al. Influência do sexo no rendimento de filetagem do bagre africano (Clarias gariepinus).
In: AQÜICULTURA BRASIL'98; CONGRESSO SUL-AMERICANO DE AQÜICULTURA, 1.; SIMPÓSIO BRASILEIRO DE AQÜICULTURA, 10., Recife. Anais... Recife: 1998, v.2. p.763-772. SOUZA, M.L.R. O que fazer com a pele de peixes? Revista Panorama da Aqüicultura, v.14, n.81, p.43-47, 2004.

TAVARES, M.P. O surubim. In: MIRANDA, M.O.T. (Ed.) Surubim. Belo Horizonte: Instituto Brasileiro do Meio Ambiente e dos Recursos Naturais, 1997. p.9-25. 